\title{
Afinal, o que é 7 terapia sexual?
}

\author{
Nelson Vitiello \\ Elisa Rodrigues Dias Oliboni \\ Sonia Daud \\ Eduardo Takeshi Yabusaki
}

Não é incomum que profissionais, especialmente os da área da assistência orgânica ou psicológica, tenham uma visão desdenhosa da Terapia Sexual, por eles encarada como forma menor de terapia, ou até mesmo de algo que beira a charlatanismo. As coisas, como pretendemos demonstrar, não são bem assim.

É por todos reconhecido que os problemas emergentes no exercício da sexualidade podem ter suas causas fundamentadas em processos orgânicos. Várias patologias, em especial as que atingem os sistemas circulatório e nervoso, além de outras condições (uso de drogas, seqüelas de cirurgias ou de traumas, etc.), interferem com a fisiologia, desencadeando o que se denomina de "disfunção sexual", isto é, a quebra da norma funcional da resposta sexual em uma ou mais de suas diferentes fases (desejo, excitação, orgasmo). Nessas situações, evidentemente, o tratamento a ser indicado deve ser o de correção dessa causa orgânica, sendo apenas ocasionalmente indicada uma forma de psicoterapia de apoio. 
Outras vezes, mesmo sendo normais os parâmetros fisiológicos de resposta, a pessoa não se encontra satisfeita com seu modelo de exercício da sexualidade, gerando o que se denomina habitualmente de "Inadequação sexual". Nessas situações, ainda que apresentem resposta sexual normal, as pessoas - ou mais freqüentemente, seus parceiros - gostariam de ter desempenho sexual diverso do que ostentam.

Finalmente, um grupo infelizmente numeroso de indivíduos, apresenta disfunções sexuais sem que existam causas de fundo orgânico que possam explicá-las. Nessas eventualidades, em que o fator causal da disfunção sexual é claramente de fundo psicossocial (educação sexual distorcida, experiências pregressas traumatizantes e outras), configure-se um tipo de disfunção sexual em que não existe a possibilidade de um tratamento por via orgânica.

Tanto nas inadequações sexuais, quanto nas disfunções sexuais de causa psicossocial, o tratamento orgânico, medicamentoso, é absolutamente ineficiente.

Claro que freqüentemente, pela interação total entre o orgânico e o psicológico, qualquer uma dessas formas acaba por comprometer a outra. Assim, disfunções orgânicas levam a problemas psicológicos e disfunções inicialmente psicogênicas terminam por comprometer o orgânico.

Em ambas as situações, as dificuldades enfrentadas por seus portadores tem um peso acentuado na qualidade de vida e no grau de felicidade de seus portadores, em especial numa sociedade machista como a nossa, na qual grande parte da auto-estima se embasa na avaliação do desempenho sexual. Por isso mesmo, essas disfunções assumem o caráter de um problema que requer resolução urgente.

No caso específico das disfunções psicogênicas, são elas claramente apenas um sintoma de um problema mais profundo. Mas um sintoma que requer rápida solução, muito mais rápida do que as formas tradicionais de psicoterapia (psicanálise tradicional, psicodrama, etc.) podem prometer. Aliás, tendo em vista o elevado grau de angústia que a disfunção sexual determina em seus portadores, não é incomum que estes apresentam grande resistência às psicoterapias convencionais.

Nesse ponto assume importância a Terapia Sexual.

O que se compreende por Terapia Sexual é na verdade um conjunto de técnicas (comportamentais, cognitivistas, corporais e outras) a ser utilizado no tratamento de um sintoma, a disfunção ou a inadequação sexual. A Terapia Sexual vê esses problemas como sintomas e se propõe a tratá-los; não tem como proposta o tratamento de fatores psicológicos mais profundos, nem pretende substituir outras formas de terapia. Tal visão se lastreia na hipótese de que, estando normais os comemorativos orgânicos, 
o sintoma disfunção sexual é uma forma inadequada de comportamento, cuja raiz está em um aprendizado distorcido, numa educação inadequada ou em experiências anteriores traumatizantes. Assim, em essência, a proposta da Terapia Sexual é promover uma "reeducação" sexual.

Reconhecida até mesmo por seus mais ardorosos defensores como forma de tratamento sintomática (visto que a disfunção sexual é apenas um sintoma), a Terapia Sexual é um tipo de terapia com resultados a curto prazo, que se compromete apenas com a resolução do sintoma, na grande maioria das vezes extremamente angustiante, levando seus portadores a uma busca desesperada de solução.

$\mathrm{Na}$ verdade, vista sob esse ângulo, a Terapia Sexual é apenas uma forma rápida de resolução de um sintoma, que permite ao paciente, se for o caso, buscar posteriormente, com mais tranqüilidade, uma forma de terapia mais profunda que posse realmente lidar com as causas psicológicas ou sociais de sua disfunção. Em alguns casos, em que a disfunção foi desencadeada por um mecanismo meramente situacional, pode ocorrer que o portador não tenha realmente maiores problemas emocionais. Nesses casos, a Terapia Sexual isoladamente pode ser suficiente.

Assim vista, a Terapia Sexual tem importante lugar no conjunto de técnicas psicoterápicas disponíveis aos profissionais da área. 